\title{
Peningkatan Hasil Belajar Siswa pada Materi Dinamika Gerak Partikel Dengan Menerapkan Model Pembelajaran Project Based Learning
}

\author{
Vina Serevina $^{\text {a) }}$, Dewi Muliyati ${ }^{\text {b) }}$ \\ Program Studi Pendidikan Fisika, Fakultas MIPA, Universitas Negeri Jakarta, Jakarta 13220 \\ Email: ${ }^{a)}$ vina_serevina77@yahoo.com, ${ }^{b}$ dmuliyati@unj.ac.id
}

\begin{abstract}
This study aims to determine improving student learning outcomes in learning physics by applying the Project Based Learning Model with Planning phases (planning), Creating (creation or implementation), and processing. The object of this research is the students of class X MIPA 3 SMA Negeri 68 Jakarta with 37 students. The research method used is Classroom Action Research with Model Chemish \& Mc.Taggart which are the phases: planning (planning), action (acting), observation (observing) and reflection (reflecting), in collaboration with the teacher of the class. The study was conducted by two cycles, the first cycle consisted of two meetings, in the second cycle two meetings, too. Data collection been done from the results of Physics of student learning, interviews and field notes. The results of this research with the achievements in materials physics of Dynamics Motion Particle, respectively in the first cycle: Average of Affective score: Scientific Attitude and motivation of students is not optimal, Average of Cognitive score of Students: 43.7 and Average of Psychomotor score of student: 45.3. Results in cycle 1 is still below The Minimum Criteria Score for completeness $(\mathrm{KKM})$ in Physics of SMAN 68 Jakarta $=75$. In Cycle II: Average Affective score of students: Attitudes Scientific is high score with the student response was quick and student motivation was optimal with high residual enthusiasm, Average Cognitive score of student: 84.5 and Average Psychomotor score of students: 83.5. The result of this research showed that by applying the Project Based Learning Model can improve student learning outcomes (affective, cognitive and Psychomotor).
\end{abstract}

Keywords: Project Based Learning Model, Result Study of Physics.

\begin{abstract}
Abstrak
Penelitian ini bertujuan untuk mengetahui peningkatan hasil belajar siswa dalam pembelajaran fisika dengan menerapkan model pembelajaran Project Based Learning dengan tahapan Planning (perencanaan), Creating (mencipta atau implementasi), dan Processing (pengolahan). Objek penelitian adalah siswa kelas X IPA 3 SMA Negeri 68 Jakarta sebanyak 37 siswa. Metode penelitian yang dipakai adalah metode penelitian tindakan kelas Model Kemis \& Mc.Taggart dngan tahap: perencanaan (planning), tindakan (acting), pengamatan (observing), dan refleksi (reflecting), yang berkolaborasi dengan guru pengajar di kelas. Penelitian dilakukan sebanyak dua siklus, pada siklus pertama terdiri dari dua kali pertemuan, pada siklus kedua dua kali pertemuan. Metode pengumpulan data dengan hasil belajar siswa, wawancara dan catatan lapangan. Hasil penelitian ini dengan capaian pada materi Fisika Dinamika Gerak Partikel, secara berturut-turut pada siklus I: Nilai Afektif Rata-rata: Sikap Ilmiah dan Motivasi siswa belum optimal, Nilai Kognitif Siswa rata-rata: 43.7 dan Nilai
\end{abstract}


Psikomotor siswa rata-rata: 45,3. Hasil pada siklus 1 masih di bawah Nilai Kriteria Ketuntasan Minimal $(K K M)$ Fisika SMAN 68 Jakarta $=75$. Pada Siklus II: Nilai Afektif Rata-rata: Sikap Ilmiah yang tinggi dengan respon yang siswa cepat dan Motivasi siswa sudah optimal dengan antusiasme sisa yang tinggi, Nilai Kognitif Siswa rata-rata Hasil Test: 84.5 dan Nilai Psikomotor siswa rata-rata: 83.5. Hasil penelitian ini menunjukkan bahwa dengan menerapkan model pembelajaran Project Based Learning dapat meningkatkan hasil belajar siswa (aspek afektif, kognitif dan Psikomotornya).

Kata-kata kunci : Model pembelajaran Project Based Learning, Hasil Belajar Fisika.

\section{PENDAHULUAN}

Tujuan pembelajaran fisika di antaranya agar siswa menguasai berbagai konsep dan prinsip fisika untuk mengembangkan pengetahuan, keterampilan, dan sikap percaya diri yang selanjutnya dapat diterapkan dalam kehidupan sehari-hari. Untuk mencapai tujuan pembelajaran ini, diperlukan model pembelajaran yang tepat, baik ditinjau dari segi waktu, konten kurikulum, dan fleksibilitas penggunaan model pembelajaran. Salah satu model pembelajaran yang dimaksud adalah project based learning, atau pembelajaran berbasis proyek.

Ellis (2008) menyatakan bahwa pembelajaran berbasis proyek merupakan ajang kesempatan berdiskusi yang diperlukan siswa, melatih siswa untuk menyelesaikan masalah, serta memberikan kesan menyenangkan dalam pembelajaran sehingga pembelajaran berbasis proyek ini dapat dijadikan strategi pembelajaran yang efektif. Secara sederhana, inti dari pembelajaran berbasis proyek yang diterapkan dalam penelitian ini terdiri dari perencanaan, implementasi, dan pengolahan (Karli dan Yuliariatiningsih, 2003). Tahapan pembelajaran ini kemudian diterapkan untuk melihat perubahanperubahan pada aspek afektif (sikap ilmiah dan motivasi belajar), kognitif (tes materi ajar) dan psikomotor (keterampilan siswa).

\section{METODE PENELITIAN}

Metode yang digunakan dalam penelitian ini adalah penelitian tindakan kelas (Classroom Action Research). Penelitian dilakukan dalam siklus-sklus yang masing-masing terdiri dari perencanaan (planning), tindakan (acting), pengamatan (observing), dan refleksi (reflecting) (Kasbolah 1999).

Penelitian ini dilaksanakan di SMAN 68 Jakarta pada kelas X MIPA 3 semester ganjil tahun ajaran 2013/2014. SMAN 68 Jakarta terletak di Jalan Salemba Raya No.18 Jakarta Pusat.

\section{Siklus I}

\section{Perencanaan}

Pada tahap perencanaan tindakan, peneliti membuat instrumen pengumpulan data berupa lembar observasi, tes kemampuan berfikir dan lembar kerja peserta didik. Membuat Rencana Pelaksanaan Pembelajaran (RPP) yang sesuai dengan model pembelajaran berbasis proyek yang akan disampaikan dalam proses pembelajaran pada materi gerak melingkar. 


\section{Pelaksanaan}

Pada tahap pelaksanaan pembelajaran peneliti menggunakan model pembelajaran berbasis proyek dengan langkah-langkah seperti pada TABEL 1.

TABEL 1. Rancangan Kegiatan Pelaksanaan Penelitian Pada Siklus I

\begin{tabular}{lll}
\hline NO & KEGIATAN & AKTIVITAS BELAJAR \\
\hline $\mathbf{1}$ & $\begin{array}{l}\text { Mengamati } \\
\text { (Observing) }\end{array}$ & $\begin{array}{l}\text { Mengamati Video roller coaster dan roda gila, aplikasi materi Dinamika } \\
\text { Gerak Partikel terkait Gerak Melingkar. }\end{array}$ \\
$\mathbf{2}$ & $\begin{array}{l}\text { Menanya } \\
\text { (Questioning) }\end{array}$ & $\begin{array}{l}\text { Diskusi kelas mengenai besaran-besaran perioda, frekuensi, kecepatan } \\
\text { linier dan kecepatan sudut. }\end{array}$ \\
$\mathbf{3}$ & $\begin{array}{l}\text { Pengumpulan data } \\
\text { (Experimenting) }\end{array}$ & Melakukan percobaan tentang gaya sentripetal \\
& $\begin{array}{l}\text { Mengasosiasi } \\
\text { (Associating) }\end{array}$ & $\begin{array}{l}\text { Membimbing peserta didik (kelompok) untuk menganalisa penyebab air } \\
\text { tidak tumpah saaat diputar-putar dengan tali }\end{array}$ \\
& Mengkomunikasikan & $\begin{array}{l}\text { Peserta didik (kelompok) dapat menyimpulkan hasil analisa } \\
\text { Mempresentasikan hasil diskusi kelompok terkait percobaan gaya } \\
\text { sentripetal } \\
\text { (Communicating) }\end{array}$ \\
& $\begin{array}{l}\text { Peserta didik dapat menyelesaikan beberapa masalah pada latihan soal } \\
\text { berupa tulisan } \\
\text { Peserta didik dibimbing guru untuk mendiskusikan project yang akan } \\
\text { dilaksanakan untuk materi selanjutnya }\end{array}$ \\
& &
\end{tabular}

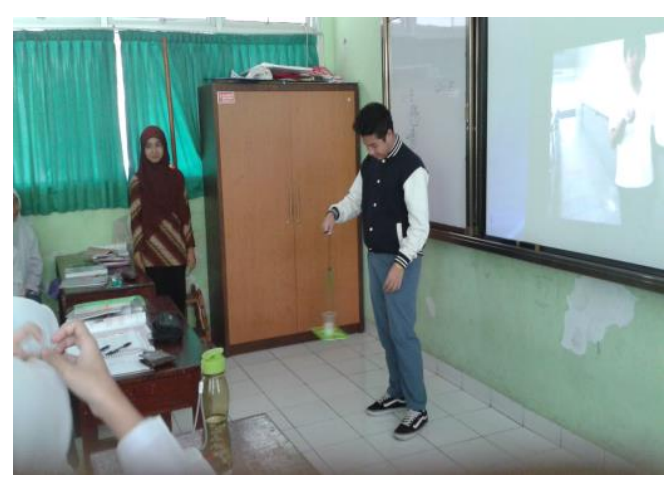

GAMBAR 1. Siswa yang berdiri Mencoba di depan Kelas, Siswayang duduk Mengamati dan Menanya

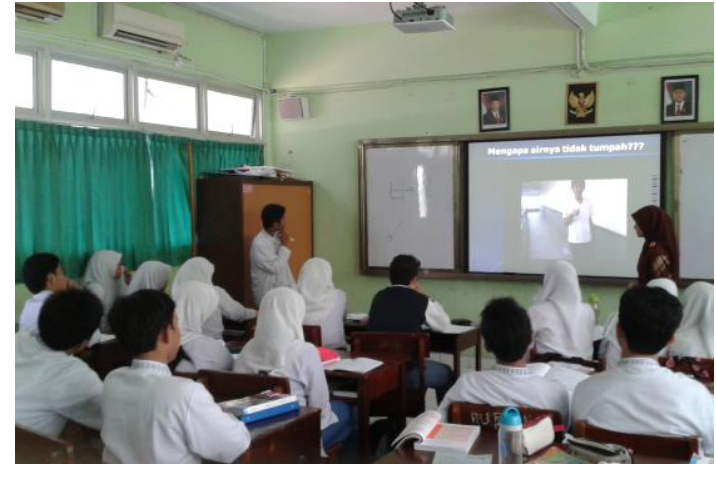

GAMBAR 2. Siswa yg duduk Mengamati dan Menanya, Yang berdiri Mengasosiasikan dan Mengkomunikasikan dengan Presentasi di Depan kelas.

\section{Pengamatan}

Pengamatan dilakukan secara kolaboratif antara pihak pengajar, yang dibantu oleh 3 orang rekan sejawat dan guru yang dilakukan bersamaan dengan tahap pelaksanaan tindakan. Foto kejadian yang terjadi diambil untuk tiap siklus, sedangkan rekaman data untuk catatan lapangan dari wawancara dengan siswa atas segala peristiwa yang terjadi selama proses pembelajaran. Hasil pengamatan dicatat ke dalam lembar observasi.

\section{Refleksi}

Peneliti memonitoring dan mengevaluasi hasil pengamatannya yang didapatkan pada siklus I kemudian membuat interpretasinya. Semua hasil pengamatan ditinjau ulang bersama-sama oleh guru, peneliti, dan rekan sejawat. Hasil refleksi digunakan untuk membantu pemecahan masalah dan perencanaan siklus II jika masih terdapat kekurangan pada siklus I. 


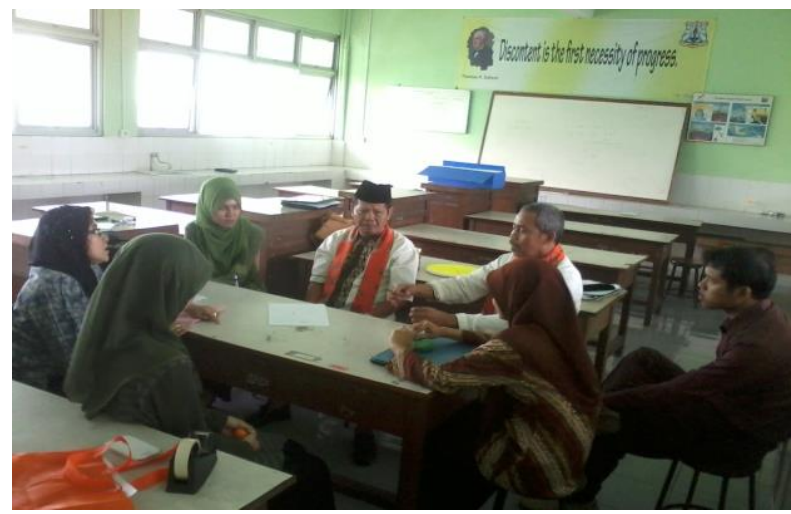

GAMBAR 3. Evaluasi Hasil Pelaksanaan Siklus 1.

\section{Siklus II}

\section{Perencanaan}

Perencanaan siklus II merupakan refleksi dari siklus I, pada tahap ini guru lebih memotivasi siswa dan melakukan kegiatan yang dapat membuat siswa lebih aktif.

\section{Pelaksanaan}

Pada tahap pelaksanaan pembelajaran peneliti menggunakan Project Based learning dengan langkah-langkah sebagai berikut:

TABEL 2. Rancangan Kegiatan Pelaksanaan Penelitian Pada Siklus II

\begin{tabular}{|c|c|c|}
\hline NO & KEGIATAN & AKTIVITAS BELAJAR \\
\hline 1 & $\begin{array}{l}\text { Mengamati } \\
\text { (Observing) }\end{array}$ & Video kincir air dan perlombaan balap sepeda \\
\hline 2 & $\begin{array}{l}\text { Menanya } \\
\text { (Questioning) }\end{array}$ & $\begin{array}{l}\text { Diskusi kelas mengenai jenis-jenis hubungan roda-roda yang ada pada } \\
\text { kehidupan sehari-hari }\end{array}$ \\
\hline 3 & $\begin{array}{l}\text { Pengumpulan data } \\
\text { (Experimenting) }\end{array}$ & $\begin{array}{l}\text { Melakukan percobaan tentang pengaruh jari-jari roda dengan kecepatan linier, } \\
\text { roda seporos dan roda yang dihubungkan dengan tali. }\end{array}$ \\
\hline 4 & $\begin{array}{l}\text { Mengasosiasi } \\
\text { (Associating) }\end{array}$ & $\begin{array}{l}\text { Membimbing peserta didik (kelompok) untuk menganalisa tentang pengaruh } \\
\text { jari-jari roda dengan kecepatan linier, kecepatan pada roda seporos dan roda } \\
\text { yang dihubungkan dengan tali. } \\
\text { Peserta didik (kelompok) dapat menyimpulkan hasil analisa }\end{array}$ \\
\hline 5 & $\begin{array}{l}\text { Mengkomunikasikan } \\
\text { (Communicating) }\end{array}$ & $\begin{array}{l}\text { Mempresentasikan hasil diskusi kelompok terkait Dinamika Gerak Partikel } \\
\text { tentang percobaan pengaruh jari-jari roda dengan kecepatan linier, roda } \\
\text { seporos dan roda yang dihubungkan dengan tali. } \\
\text { Peserta didik dapat menyelesaikan beberapa masalah pada latihan soal berupa } \\
\text { tulisan } \\
\text { Peserta didik dapat menyebutkan aplikasi lain dari dinamika gerak pertikel. }\end{array}$ \\
\hline
\end{tabular}




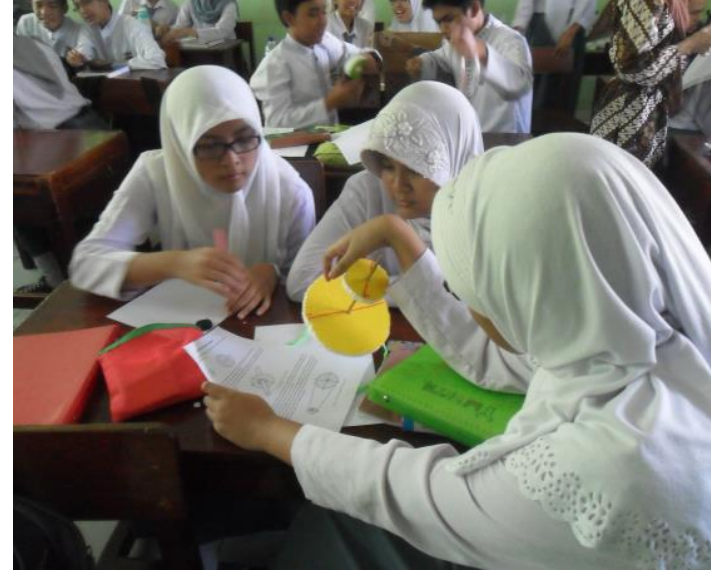

GAMBAR 4. Siswa aktif membuat Alat sendiri (Project Based Learning).

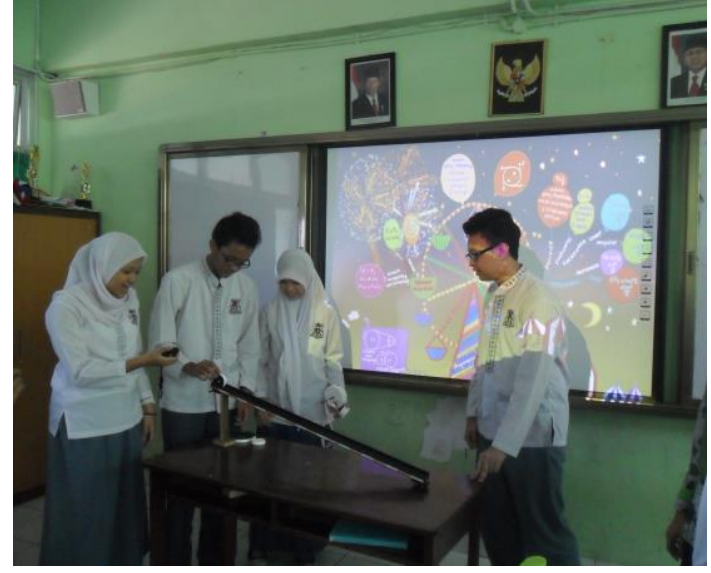

GAMBAR 5. Siswa membuat Project dan mempresentasikan di depan Kelas.

\section{Pengamatan}

Pengamatan yang dilakukan masih sama seperti siklus I. Mencatat temuan-temuan baru yang terjadi selama proses pembelajaran. Data hasil pengamatan dikumpulkan untuk diolah dan dianalisis.

\section{Refleksi}

Indikator keberhasilan sudah tercapai maka siklus dihentikan.

\section{HASIL PENELITIAN DAN PEMBAHASAN}

Setelah dilaksanakan Penelitian Tindakan Kelas ini dengan dua siklus maka diperoleh data berdasarkan metode triangulasi data, yaitu:

\section{Data Peristiwa}

Penelitian ini merupakan penelitian tindakan kelas (classroom action research) menggunakan prosedur yang dikembangkan oleh Kemmis dan Taggrat (1990) dengan rancangan bersiklus yang akan dihentikan jika sudah terdapat atau tercapai indikatornya, dalam hal ini hasil belajar siswa sudah mencapai nilai KKM Fisika 75. Penelitian ini dilaksanakan pada tanggal 15 November 2013 (Siklus I) dan 22 November 2013 (Siklus II) di SMAN 68 Jakarta yang terletak di Jalan Salemba Raya No.18 Jakarta Pusat. Objek penelitiannya adalah anak-anak kelas X MIPA 3 semester ganjil tahun pelajaran 2013/2014. SMAN 68 Jakarta.

Pada penelitian ini hasil belajar terhadap materi dinamika gerak partikel diujicobakan dengan tindakan tes untuk mendapatkan hasil belajar siswa. Penelitian dilaksanakan dalam dua siklus yang diantaranya kedua siklus dilakukan refleksi dengan maksud untuk mempertajam tindakan agar dapat diperoleh data yang benar-benar menggambarkan keberhasilan metode. Adapun perolehan hasil belajar siswa sebagai berikut:

TABEL 3. Data Perolehan Hasil Belajar Siswa pada Siklus I dan Siklus II

\begin{tabular}{lll}
\hline Aspek Penilaian & Siklus I & Siklus II \\
\hline Kognitif (Post test) & 43,7 & 84,5 \\
Psikomotor (Demonstrasi) & 45,3 & 83,5 \\
Afektif (Sikap Ilmiah dan Motivasi & $\begin{array}{l}\text { Penilaian terhadap sikap ilmiah } \\
\text { Siswa) } \\
\text { dan motivasi siswa belum }\end{array}$ & $\begin{array}{l}\text { Penilaian terhadap sikap ilmiah } \\
\text { optimal. }\end{array}$ \\
& & Hampir seluruh siswa \\
& & menunjukkan antusias tinggi \\
& & dalam mengikuti pembelajaran. \\
\hline
\end{tabular}




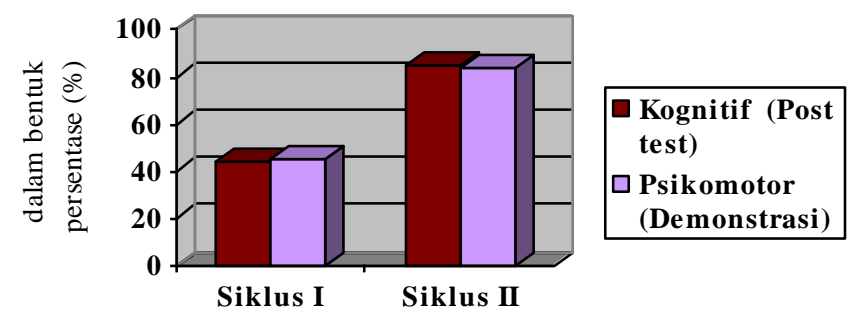

GAMBAR 6. Grafik Hasil Belajar Siswa.

\section{Data Wawancara}

Penelitian ini didukung oleh hasil wawancara terhadap beberapa objek seperti siswa dan guru. Adapun hasil wawancaranya sebagai berikut:

\section{Responden Guru}

Ada tiga pertanyaan yang diajukan kepada 3 guru yaitu sebagai berikut: (1) Setujukah Bapak/Ibu jika komposisi Kegiatan Belajar Mengajar lebih banyak bereksperimen (melakukan percobaan di laboratorium) dari pada teoritis (ceramah di kelas)? Jawaban guru pun bervariasi yaitu diantaranya dua orang guru menjawab setuju, karena aplikasi penerapan (praktikum) itu memacu anak-anak untuk aktif dalam bekerja dan mengasah pemahaman teori. Sedangkan satu guru menjawab tidak setuju, karena fisika lebih banyak pada perhitungan matematis yang sangat membutuhkan waktu banyak untuk dijelaskan. (2) Menurut Bapak/Ibu, apakah penggunaan media pembelajaran dapat berdampak baik bagi pemahaman siswa terhadap fisika? Semua guru menjawab ya. Bahwa media pembelajaran sangat berdampak baik bagi pemahaman siswa. (3) Apakah pembelajaran fisika yang telah Bapak/Ibu ajarkan kepada siswa sudah berpusat pada aktivitas siswa (riset, proyek)? Mayoritas guru menjawab ya, sudah terealisasikan.

\section{Responden Siswa}

Ada tiga pertanyaan yang diajukan kepada 5 siswa yaitu sebagai berikut: (1) Apakah menurut anda dengan bantuan media pembelajaran dapat meningkatkan pemahaman konsep fisika? Semua siswa menjawab ya, bahwa media sangat membantu sekali dalam pembelajaran. (2) Apakah dengan cara guru mengajar menggunakan metode baru seperti ini (inquiry, constructivism dan learning community) anda merasa senang dan menjadi semakin mengerti akan konsep materi tersebut? Semua siswa menjawab ya, mereka sangat senang dan menjadi semakin paham akan konsep materi tersebut. (3) Setujukah anda jika guru kedepannya lebih kreatif lagi dalam mengajar, khususnya dalam mengembangkan metode-metode pembelajaran yang baru agar tidak monoton dan siswa tidak cepat bosan dalam belajar? Semua siswa menjawab ya sangat setuju. Guru kreatif akan melahirkan generasi yang cerdas. 


\section{KESIMPULAN}

Implementasi model pembelajaran Project Based Learning di Kelas X MIPA 3 SMAN 68 Jakarta, secara umum mengalami peningkatan hasil belajar siswa yang sudah mencapai nilai KKM 75 dengan persentase capaian pada materi Fisika Dinamika Gerak Partikel, secara berturut-turut pada siklus I: Nilai Afektif Rata-rata: Sikap Ilmiah dan Motivasi siswa belum optimal, Nilai Kognitif Siswa ratarata: 43.7 dan Nilai Psikomotor siswa rata-rata: 45,3. Pada Siklus II: Nilai Afektif Rata-rata: Sikap Ilmiah yang tinggi dengan respon yang cepat dari siswa dan Motivasi siswa sudah optimal dengan antusiasme sisa yang tinggi, Nilai Kognitif Siswa rata-rata Hasil Test: 84.5 dan Nilai Psikomotor siswa rata-rata: 83.5. Sebagai saran kepada guru agar selalu meningkatkan pengetahuan, kemampuan mengajarnya dan kemampuan dalam membimbing siswa. Guru diharapkan mampu dan mau menggunakan strategi, metode serta model pembelajaran sesuai dengan mata pelajaran ataupun pokok bahasannya.

\section{REFERENSI}

Ellis, T. J. dan W. Hafner. 2008. "Building A Framework to Support Project-Based Collaborative Learning Experiences in An Asynchronous Learning Network (ALN)". Interdisciplinary Journal of E-Learning and Learning Objects. Vol.4. Tersedia pada: http://ijklo.org/volume4/IJELLOv4p167-190Eliis454.pdf.

Karli, H. dan Yuliariatiningsih, M.S. (2003). Model-Model Pembelajaran. Bandung : Bina Media Informasi.

Kasbolah, K. (1999). Penelitian Tindakan Kelas (PTK), Jakarta: Proyek Pendidikan Guru Sekolah Dasar, Dirjen Dikti, Depdikbud. 
